\title{
Application of Team-Based Learning Method in Operating Rooms
}

\author{
Ezgi Ucar Tas ${ }^{1(\underline{I D})}$ \\ ${ }^{1}$ Department of General Surgery, Fatsa State Hospital, Ordu, Turkey
}

Copyright@ Author(s) - Available online at https://dergipark.org.tr/en/pub/mbsjohs Content of this journal is licensed under a Creative Commons Attribution-NonCommercial 4.0 International License,

Received: 6 May 2021, Accepted: 12 June 2020, Published online: 31 August2021 (C) Ordu University Institute of Health Sciences, Turkey, 2021

\begin{abstract}
Team-Based Learning (TBL) is a constructivist learning method designed to shift the focus of time spent in the classroom from lecturing to student-led small group sessions. With the TBL method applied in the operating room, students can have the opportunity to closely observe the application of the knowledge they have acquired and even actively participate in the application. In addition, it should be kept in mind that the possibility of situations that may get out of control is higher in surgical applications.
\end{abstract}

Key words: Team-Based Learning, operating room

Suggested Citation Uçar Tas E. Application of Team-Based Learning Method in Operating Rooms. Mid Blac Sea J of Health Sci, 2021; 7(1):308-310

\section{Address for correspondence/reprints:}

Ezgi Ucar Tas

Telephone number: $+90(505) 8180762$

E-mail: ezgiucartas@gmail.com

\section{Letter to Editor}

Recently, many active learning methods have been used in medical faculties besides the traditional learning method. This situation can be associated with the increase in the number of students, the desire to make the learning process more effective and memorable, ensuring that the acquired knowledge can be used effectively by students and enabling students to develop solution-oriented attitudes. One of these methods, Team Based Learning (TBL) is a constructivist learning method designed to shift the focus of the time spent in the classroom from lecturing to student-led small group sessions. In addition, in this method, it is not necessary to reduce the size of the classes, to increase the number of instructors and the duration of the lessons (1).

Participation of students and educators in the learning process and their interaction with each other is higher in TBL compared to the traditional lesson method (2). Complex course subjects that students will have difficulty understanding on their own are explained 
by the instructor in a systematic and understandable way in the traditional lesson method. It has been observed that some students tend to overlook important issues in the TBL method. However, TBL is excellent at encouraging students to come prepared, participate actively and collaborate with each other. Both methods can be applied together in a way that one's strengths complement the other's weaknesses (3). While in traditional lesson methods, students usually come unprepared for the lesson, in active learning methods such as TBL, almost all students prepare before the lesson and participate in the class (4).

Comparing the problem-based learning (PBL) and team-based learning (TBL) methods, both of which are known to be active participatory learning methods; The instructor does not have to be an expert in PBL. Since there should be 1-2 instructors for each group in PBL, the number of instructors needed is high. A single expert instructor is sufficient for TBL. In PBL, the role of the instructor in correcting the missing information is not as effective as in TBL. While in PBL, students reach a predetermined goal, in TBL, students set their own goals and participate in the lesson (5). Zgheib et al. applied the TBL method to first and second year medical students for two years. It has been observed that the TBL method contributes to the development of self-learning, problem solving and communication skills of medical students. It was determined that there was a continuous and cumulative improvement in the teamwork skills of students after a period of time (6). The TBL

method can be applied in surgery branches, also in the operating room (7). In the TBL method applied in surgical internship, the students mostly evaluated this method as good or excellent. It has been observed that studying after this application is easier and this is a good opportunity for interactive learning (8).

With the TBL method applied in the operating room during the surgical internship, the applications can be made easier to learn for the students.In this way, students can have the opportunity to closely observe how the surgeries are performed and even actively participate in the practice. Surgical operations are applications that may require an intervention to the patient in a very short time in emergency situations. Therefore these applications are vital. When students are in this environment, they can become more aware of the event and comprehend the effectiveness of the information they have acquired in a short time. For this reason, the use of such learning methods, especially in practice-oriented branches such as surgery, can contribute to the learning process at a high level. However, difficulties may be encountered during application due to factors such as the stressful environment of the operating room, emergency interventions, surgical hierarchy and sterilization rules. Depending on these factors, instructors or operating room staff may unintentionally react suddenly and harshly to students. This situation can negatively impact students who are at the beginning of educational life. Accordingly, it can be ensured that the operation type is selected over stable cases as much as possible and the personality traits of the trainer are suitable for this situation. Such learning methods in surgical applications can be both more effective and more interesting for students than other branches. However, it should be kept in mind that the possibility of situations that may get out of control is higher in surgical applications.

Peer-review: Externally peer-reviewed.

Author Contributions: Concept, Design, Supervision, Literature Review, Writing, Critical Review- E.U.T.

Conflict of Interest: No conflict of interest was declared by the authors.

Financial Disclosure: The authors declared that this study hasn't received no financial support.

\section{References}

1. Malone E, Spieth A. Team-based learning in a subsection of a veterinary course as compared to standard lectures. Journal of Scholarship of Teaching and Learning. 2012;12(3):88-107.

2. Kelly PA, Haidet P, Schneider V, Searle N, Seidel $\mathrm{CL}$, Richards BF. A comparison of in-class learner engagement across lecture, problem-based learning, and team learning using the STROBE classroom observation tool. Teaching and learning in medicine. 2005;17(2):112-8.

3. Yang LH, Jiang LY, Xu B, Liu SQ, Liang YR, Ye $\mathrm{JH}$, et al. Evaluating team-based, lecture-based, and hybrid learning methods for neurology clerkship in China: a method-comparison study. BMC medical education. 2014;14(1):98.

4. DeJongh B, Lemoine N, Buckley E, Traynor L. Student preparation time for traditional lecture versus team-based learning in a pharmacotherapy course. Currents in Pharmacy Teaching and Learning. 2018;10(3):360-6

5. Abdelkhalek N, Hussein A, Gibbs T, Hamdy H. Using team-based learning to preparemedical students for future problem-based learning. Medical teacher. 2010;32(2):123-9. 
6. Zgheib NK, Dimassi Z, Bou Akl I, Badr KF, Sabra R. The long-term impact of team-based learning on medical students' team performance scores and on their peer evaluation scores. Medical teacher. 2016;38(10):1017-24.

7. Arani ZA, Hoseini MHM, Afra LG, Mohammadzade M. The effect of teaching on team-based learning and group discussion on learning and academic motivation of operating room students in the technology of gastrointestinal surgery lesson. Journal of Nursing and Midwifery Sciences. 2019;6(2):72.

8. Kaminski AD, Babbitt KM, McCarthy MC, Markert RJ, Roelle MP, Parikh PP. Team-based learning in the surgery clerkship: impact on student examination scores, evaluations, and perceptions. Journal of surgical education. 2019;76(2):408-13. 